\title{
Stereospecific Polymerization of Stereoregular Poly(methyl methacrylate) Macromonomer and Determination of Main-Chain Tacticity of Resulting Polymacromonomer
}

\author{
Tatsuki Kitayama, Osamu Nakagawa, and Koichi Hatada \\ Department of Chemistry, Faculty of Engineering Science, Osaka University, \\ Toyonaka, Osaka 560, Japan
}

(Received August 14, 1995)

\begin{abstract}
Highly isotactic and syndiotactic poly(methyl methacrylate) (PMMA) macromonomers having methacryloyl group as a polymerizable function were synthesized from the corresponding $\mathrm{PMMA}$ living anions prepared with $t-\mathrm{C}_{4} \mathrm{H}_{9} \mathrm{MgBr}$ and $t-\mathrm{C}_{4} \mathrm{H}_{9} \mathrm{Li} /\left(n-\mathrm{C}_{4} \mathrm{H}_{9}\right)_{3} \mathrm{Al}$, respectively, in toluene at $-78^{\circ} \mathrm{C}$. Anionic polymerization of the stereoregular PMMA macromonomers was examined to obtain comblike polymers which are stereoregular with respect to the main chain as well as the side chains. Polymerization with 1,1-diphenylhexyllithium in tetrahydrofuran at $-78^{\circ} \mathrm{C}$ gave comblike polymers with syndiotactic main chain and polymerization with $t-\mathrm{C}_{4} \mathrm{H}_{9} \mathrm{MgBr}$ in toluene at $-78^{\circ} \mathrm{C}$ gave comblike polymers with isotactic main chain. Tacticities of the main chain of the resulting polymacromonomers were determined by ${ }^{1} \mathrm{H}$ NMR spectroscopic analyses of the polymers of totally deuterated PMMA macromonomers with undeuterated methacryloyl function.

KEY WORDS Macromonomer/Comblike Polymer / Polymacromonomer / Stereoregularity / Anionic Polymerization / Deuterated Macromonomer / Poly(methyl methacrylate) / Nuclear Magnetic Resonance /
\end{abstract}

Use of macromonomer provides one of the most effective methods for the structural control of comblike polymer and graft polymer. ${ }^{1-14}$ Even though many investigations have been reported on the preparation and polymerization of macromonomer, little attention has been paid to the stereoregularity of macromonomer and polymacromonomer obtained therefrom. ${ }^{6-14}$ The control of side-chain stereoregularity of polymacromonomer has become attainable by the use of stereoregular macromonomers which are prepared by stereospecific polymerization with initiators having polymerizable function ${ }^{6,7,13}$ and by stereospecific living polymerization followed by end-capping with functional terminators. ${ }^{8,10,12-14}$ On the other hand, the control of stereoregularity in the main chain of polymacromonomer should be more difficult and has been a challenging research objective.

We have reported the anionic polymerizations of polyisobutylene macromonomer having methacryloyl group, which is feasible for stereospecific polymerization via proper selection of initiator and polymerization conditions. ${ }^{15,16}$ The polymerizations afforded comblike polymers with stereoregular main chain. ${ }^{11,13}$ Recently, we reported the preparation of graft polymers with stereoregular main chain and side chains by stereospecific anionic copolymerization of stereoregular poly(methyl methacrylate) (PMMA) macromonomers having methacryloyl function with methacrylate monomers. ${ }^{12-14}$ In the present study, we carried out homopolymerization of the stereoregular PMMA macrornonomers to obtain stereoregular comblike polymers. Direct NMR determination of the main-chain tacticity of the polymacromonomers was difficult because NMR signals of the main-chain monomeric units overlapped severely with those of the side-chain units. To overcome this difficulty, macromonomers of totally deuterated monomer with undeuterated methacryloyl function were prepared and polymerized under the same conditions and the polymacromonomers were analyzed by ${ }^{1} \mathrm{H}$ NMR spectroscopy.

\section{EXPERIMENTAL}

\section{Materials}

Toluene and benzene, purified in the usual manner, were mixed with a small amount of $n-\mathrm{C}_{4} \mathrm{H}_{9} \mathrm{Li}$ and distilled under vacuum immediately before use. Tetrahydrofuran (THF), purified by distillation from calcium hydride $\left(\mathrm{CaH}_{2}\right)$, was distilled again over lithium aluminum hydride and vacuum-distilled just before use. $t-\mathrm{C}_{4} \mathrm{H}_{9} \mathrm{MgBr}$ was synthesized from $t-\mathrm{C}_{4} \mathrm{H}_{9} \mathrm{Br}$ and $\mathrm{Mg}$ in diethyl ether. ${ }^{17}$ 1,1-Diphenylhexyllithium (DPHLi) was prepared in THF at $0^{\circ} \mathrm{C}$ from 1,1-diphenylethylene and $n-\mathrm{C}_{4} \mathrm{H}_{9}$ Li. $^{18-20}$

Isotactic (it-) and syndiotactic (st-) PMMA macromonomers were prepared from the corresponding PMMA living anions. The detailed procedures were described in the previous papers. ${ }^{12,14}$ The characteristics of the macromonomers used in the present study were summarized in Table I as captions.

Totally deuterated methyl methacrylate $\left(\mathrm{MMA}-d_{8}\right)$ was a generous gift from Mitsubishi Rayon Co., Inc., purified in the usual manner, dried over $\mathrm{CaH}_{2}$, and then distilled under vacuum immediately before use. Deuterated $i t$ - and $s t$-PMMA macromonomers were prepared from the MMA- $d_{8}$ in the similar manners to those for the non-deuterated macromonomers, and have nondeuterated methacryloyl function as shown below (eq 1). The characteristics of the deuterated macromonomers used were summarized in Table II as captions.

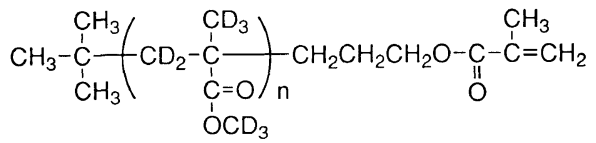

The degree of deuteration determined by the ${ }^{1} \mathrm{H}$ NMR coaxial tubing method ${ }^{21}$ for $\alpha$-methyl, methylene, and 
Table I. Anionic polymerizations of stereoregular PMMA macromonomers (Mac) ${ }^{\mathrm{a}}$

\begin{tabular}{|c|c|c|c|c|c|c|c|c|}
\hline \multirow{2}{*}{$\mathrm{Mac} / \mathrm{mmol}$} & \multicolumn{2}{|c|}{ Conversion $/ \%$} & \multicolumn{2}{|c|}{$\bar{M}_{n}$} & \multirow{2}{*}{$\bar{M}_{w}^{\mathrm{b}}$} & \multirow{2}{*}{$\frac{\bar{M}_{w}^{\mathrm{b}}}{\bar{M}_{n}}$} & \multicolumn{2}{|c|}{$D P$ (Main chain) } \\
\hline & NMR & GPC & LALLS & NMR & & & Obsd & Calcd \\
\hline \multicolumn{9}{|c|}{ Initiator, DPHLi; solvent, THF; time, 7 days } \\
\hline$s t^{\mathrm{c}}(0.174)$ & 96 & 87 & 43300 & 44800 & 55100 & 1.27 & $13.1^{\mathrm{e}}$ & 4.8 \\
\hline$i t{ }^{\mathrm{d}}(0.122)$ & 100 & 72 & 29500 & 24500 & 36400 & 1.23 & $7.73^{\mathrm{e}}$ & 5.0 \\
\hline \multicolumn{9}{|c|}{ Initiator, $t-\mathrm{C}_{4} \mathrm{H}_{9} \mathrm{MgBr}$; solvent, toluene; time, 23 days } \\
\hline$s t^{-\mathrm{f}}(0.292)$ & 48 & 47 & 21100 & - & 28100 & 1.33 & $5.96^{\mathrm{b}}$ & 2.4 \\
\hline$i t^{-\mathrm{g}} \quad(0.253)$ & 100 & 78 & 35700 & - & 43700 & 1.23 & $9.66^{b}$ & 5.0 \\
\hline
\end{tabular}

${ }^{\mathrm{a}}[\mathrm{M}]_{0}=0.05\left(\mathrm{~mol} \mathrm{l}^{-1}\right),[\mathrm{M}]_{0} /[\mathrm{I}]_{0}=5.0$, temperature, $-78^{\circ} \mathrm{C}$. ${ }^{\mathrm{b}}$ Determined by GPC-LALLS. ${ }^{\mathrm{c}} \bar{M}_{n}=3400, \mathrm{DP}=32.1, \bar{M}_{w} / \bar{M}_{n}=1.07$, $m m: m r: r r=1: 10: 89$, functionality $=0.89 .{ }^{\mathrm{d}} \bar{M}_{n}=3140, \mathrm{DP}=29.5, \bar{M}_{w} / \bar{M}_{n}=1.21, m m: m r: r r=94: 3: 3$, functionality $=0.89$. ${ }^{\mathrm{c}}$ Determined by ${ }^{1} \mathrm{H}$ NMR. ${ }^{\mathrm{f}} \bar{M}_{n}=3530, \mathrm{DP}=33.4, \bar{M}_{w} / \bar{M}_{n}=1.13, m m: m r: r r=1: 11: 88$, functionality $=0.92 .{ }^{\mathrm{g}} \bar{M}_{n}=3690, \mathrm{DP}=35.0, \bar{M}_{w} / \bar{M}_{n}=1.17, m m: m r: r r=93:$ $5: 2$, functionality $=0.84$.

Table II. Characteristics of polymers of deuterated PMMA macromonomers (Mac- $d$ ) prepared with DPHLi in THF $[\mathrm{A}]^{\mathrm{a}}$ and with $t-\mathrm{C}_{4} \mathrm{H}_{9} \mathrm{MgBr}$ in toluene $[\mathrm{B}]^{\mathrm{b}}$

\begin{tabular}{|c|c|c|c|c|c|c|c|c|}
\hline \multirow{3}{*}{$\begin{array}{c}\text { Mac-d } \\
{[\text { Polymn] }}\end{array}$} & \multirow{2}{*}{\multicolumn{2}{|c|}{$D P$}} & \multicolumn{6}{|c|}{ Tacticity $/ \%{ }^{\mathrm{e}}$} \\
\hline & & & \multicolumn{3}{|c|}{ Main chain } & \multicolumn{3}{|c|}{ Side chain } \\
\hline & Main chain ${ }^{\mathrm{c}}$ & Side chain ${ }^{\circ}$ & $m m$ & $m r$ & $r r$ & $\mathrm{~mm}$ & $m r$ & $r r$ \\
\hline$s t{ }^{\mathrm{f}}{ }^{\mathrm{A}}[\mathrm{A}]$ & 26.3 & 25.8 & 1 & 21 & 78 & 0 & 13 & 87 \\
\hline$i t \sim^{\mathrm{g}} \quad[\mathrm{A}]$ & 37.4 & 26.7 & 8 & 17 & 75 & 93 & 6 & 1 \\
\hline$s t t^{\mathrm{f}}[\mathrm{B}]$ & 15.0 & 25.8 & 69 & 21 & 10 & 0 & 13 & 87 \\
\hline$i t^{-\mathrm{g}}[\mathrm{B}]$ & 34.6 & 26.7 & 69 & 22 & 9 & 93 & 6 & 1 \\
\hline
\end{tabular}

${ }^{\mathrm{a}}[\mathrm{M}]_{0}=0.075\left(\mathrm{~mol} \mathrm{l}^{-1}\right),[\mathrm{M}]_{0} /[\mathrm{I}]_{0}=20$, temperature, $-78^{\circ} \mathrm{C} .{ }^{\mathrm{b}}[\mathrm{M}]_{0}=0.075\left(\mathrm{~mol} \mathrm{l}^{-1}\right),[\mathrm{M}]_{0} /[\mathrm{I}]_{0}=15$, temperature, $-78^{\circ} \mathrm{C}$. ${ }^{\mathrm{c}}$ Determined by GPC-LALLS. ${ }^{\mathrm{d}}$ Determined by GPC. ${ }^{\mathrm{e}}$ Determined by ${ }^{1} \mathrm{H}$ NMR. ${ }^{\mathrm{f}} \bar{M}_{n}=2970, \bar{M}_{w} / \bar{M}_{n}=1.04$, functionality $=0.98 .{ }^{\mathrm{g}} \bar{M}_{n}=3070, \bar{M}_{w} / \bar{M}_{n}=1.06$, functionality $=0.85$.

methoxy groups were $99.07 \%, 99.12 \%$, and $99.81 \%$, respectively.

\section{Polymerization of Stereoregular PMMA Macromonomer}

The purification procedure of the stereoregular PMMA macromonomer including the deuterated macromonomer was similar to the case of copolymerization of the macromonomer described previously. ${ }^{12}$ The macromonomer was dissolved in a polymerization solvent in a glass ampoule filled with dry nitrogen and then the polymerization was initiated by adding an initiator to the mixture at $-78^{\circ} \mathrm{C}$. The polymerization reaction was quenched by adding a small amount of methanol containing $\mathrm{HCl}\left(1 \mathrm{~mol} \mathrm{l}^{-1}\right)$ after a certain polymerization time. Then, the solvent was removed under vacuum and the resulting mixture was dissolved in benzene. After removing insoluble materials by centrifugation, the product mixture was recovered from the benzene solution by freeze-drying. The polymacromonomer was fractionated from the product mixture by repeated reprecipitations in toluene-hexane mixture $(1: 1)$.

\section{Measurements}

${ }^{1} \mathrm{H}$ NMR spectra of the polymers were recorded on a JNM GSX270 NMR spectrometer (JEOL) at $270 \mathrm{MHz}$ or a JNM GX500 NMR spectrometer (JEOL) at $500 \mathrm{MHz}$.

Gel permeation chromatography (GPC) was performed on a JASCO 880-PU chromatograph equipped with Shodex GPC columns KF-80M $(30 \mathrm{~cm} \times 0.80 \mathrm{~cm})$ and KF-802.5 $(30 \mathrm{~cm} \times 0.80 \mathrm{~cm})$ with maximum porosities of $2 \times 10^{7}$ and $2 \times 10^{4}$, respectively, using THF as an eluent at $40^{\circ} \mathrm{C}$. GPC-low angle laser light scattering (GPCLALLS) experiments were run on the GPC system equipped with a TOSOH LS-8000 light scattering photometer as a detector. For determination of number- $\left(\bar{M}_{n}\right)$ and weight- $\left(\bar{M}_{w}\right)$ average molecular weights, a machine constant of the detector $\left(K_{0}\right)$ was determined by using a polystyrene (PSt) standard sample $\left(\bar{M}_{w}=110000\right.$, Polysciences Inc.). To obtain a machine constant for PMMA $(K)$, the machine constant for PSt was further corrected as $K=0.477 K_{0}$ for the difference in $\Delta n / c$ ( $\Delta n$, difference in refractive indices between a polymer and THF, $c$, concentration); $(\Delta n / c)_{\mathrm{PMMA}} /(\Delta n / c)_{\mathrm{PSt}}=0.477$, which was given in the instrument manual of the TOSOH LS- 8000 .

\section{RESULTS AND DISCUSSION}

\section{Polymerization of Stereoregular PMM A Macromonomer}

Polymerizations of stereoregular PMMA macromonomers were carried out with DPHLi in THF at $-78^{\circ} \mathrm{C}$ and with $t-\mathrm{C}_{4} \mathrm{H}_{9} \mathrm{MgBr}$ in toluene at $-78^{\circ} \mathrm{C}$. The results are summarized in Table I.

The conversions of the macromonomers could be determined by the analysis of signal intensity of the vinylidene protons in the ${ }^{1} \mathrm{H}$ NMR spectra of the polymerization products. The conversions of it- and st-PMMA macromonomers in the polymerization with DPHLi in THF were almost quantitative; $100 \%$ and $96 \%$, respectively (Table I). Thus the results provide no information on tacticity dependence of reactivities of the stereoregular macromonomers. On the other hand, the conversions of $i t$ - and $s t$-macromonomers in the polymerization with $t-\mathrm{C}_{4} \mathrm{H}_{9} \mathrm{MgBr}$ in toluene showed 
significant difference; $100 \%$ for it-macromonomer and $48 \%$ for $s t$-macromonomer. The results suggest that reactivity of it-PMMA macromonomer is higher than that of st-one. We have reported that a styrene-type it-PMMA macromonomer showed higher reactivity than the corresponding st-PMMA macromonomer in radical polymerization and copolymerization with styrene, ${ }^{8,10,13}$ and Ziegler polymerization, ${ }^{13}$ which was ascribed to the higher segmental mobility of it-PMMA chain. ${ }^{22} \mathrm{Re}-$ cently, we found that it-PMMA macromonomer with methacryloyl function showed higher reactivity than the corresponding st-one in the anionic copolymerization with methacrylate monomer. ${ }^{12,14}$ These results apparently mean that the it-PMMA macromonomers have higher reactivity than the st-ones irrespective either of polymerizable function or polymerization mechanism.

Figure 1a shows a GPC chromatogram of the product mixture from the polymerization of st-PMMA macromonomer with DPHLi in THF. The chromatogram indicates the presence of a low-molecular-weight fraction whose peak area corresponds to $23 \%$ of the total. By taking the functionality of the starting macromonomer into account, the conversion of the macromonomer could be estimated as $87 \%$ from the comparison of peak intensities of the polymacromonomer and the lowmolecular-weight fraction. The value is smaller than that determined by ${ }^{1} \mathrm{H}$ NMR $(96 \%)$, indicating that the low-molecular-weight fraction contains not only the PMMA without functional group but also the unimer which was formed by the attack of the initiator but failed to propagate further. This phenomenon was also observed in other cases (Table I).

The difference of the conversions determined by NMR and GPC is larger for the it-macromonomer than the $s t$-macromonomer irrespective of the polymerization conditions. This result indicates that impurities contained in the starting macromonomer is the most important cause of the unintentional quenching of the initiating species. The number of active chains formed in the polymerization of the $i t$-macromonomer with $t-\mathrm{C}_{4} \mathrm{H}_{9} \mathrm{MgBr}$ is smaller than that of the $s t$-macromonomer, as estimated by the number of polymacromonomer molecule formed. In spite of the smaller number of active species, the conversion of the it-macromonomer is higher than that of the $s t$-macromonomer under the same conditions as described above, suggesting undoubtedly the higher reactivity of the $i t$-macromonomer than the st-macromonomer.

The polymacromonomers could be fractionated from the product mixtures by repeated precipitation in tolu-

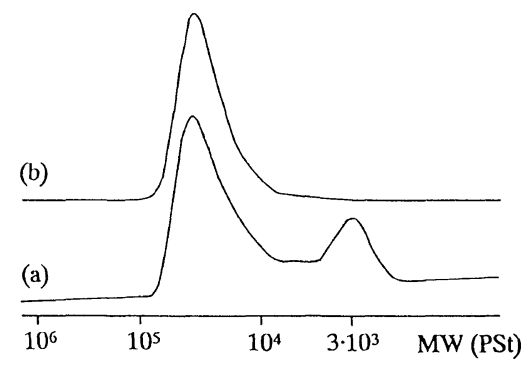

Figure 1. GPC chromatograms of the polymerization mixture of st-PMMA macromonomer with DPHLi in THF (a) and the polymacromonomer fractionated therefrom (b). ene-hexane mixtures, as evidenced by the GPC curve of the polymacromonomer shown in Figure $1 \mathrm{~b}$.

$\bar{M}_{n}$ and $\bar{M}_{w}$ values of the polymacromonomers were determined by GPC-LALLS. Number average degree of polymerization $(D P)$ of the main chain, i.e., number of branches per molecule $\left(N_{\mathrm{br}}\right)$ could be determined from the $\bar{M}_{n}$ values of the polymacromonomer and the starting macromonomer (Table I). The $D P$ values of the polymacromonomers are larger than those expected from the feed ratio of the macromonomer to the initiator and the conversion due to the unintentional quenching by impurities.

In the case of the polymacromonomers prepared with DPHLi in THF, $\bar{M}_{n}$ 's were also determined from the end-group analysis by ${ }^{1} \mathrm{H}$ NMR spectroscopy. Figure 2 shows ${ }^{1} \mathrm{H}$ NMR spectrum of the polymacromonomer prepared from it-PMMA macromonomer with DPHLi in THF. The $D P$ of the main chain of the polymacromonomer could be determined from the signal intensities of phenyl protons of the initiator fragment $(7.00-7.43 \mathrm{ppm})$ and $t-\mathrm{C}_{4} \mathrm{H}_{9}$ protons of the branch end of the macromonomer unit $(0.85 \mathrm{ppm})$. Though the phenyl proton signal overlapped with the signal due to the remaining $o$-protons in nitrobenzene- $d_{5}(7.35 \mathrm{ppm})$, the contribution of the latter signal could be subtracted based on the signal intensity of $m$-protons in nitrobenzene- $d_{5}(7.97 \mathrm{ppm})$. Thus, the $\bar{M}_{n}$ value was determined according to eq 2 .

$$
\begin{aligned}
\bar{M}_{n} & =(D P \text { of main chain }) \times\left(\bar{M}_{n} \text { of macromonomer }\right) \\
& +(\text { molecular weight of initiator fragment })+1
\end{aligned}
$$

The values agreed well with those determined by GPC-LALLS (Table I), confirming that the end-group structure of the polymacromonomer is well predictable as follows eq 3 .
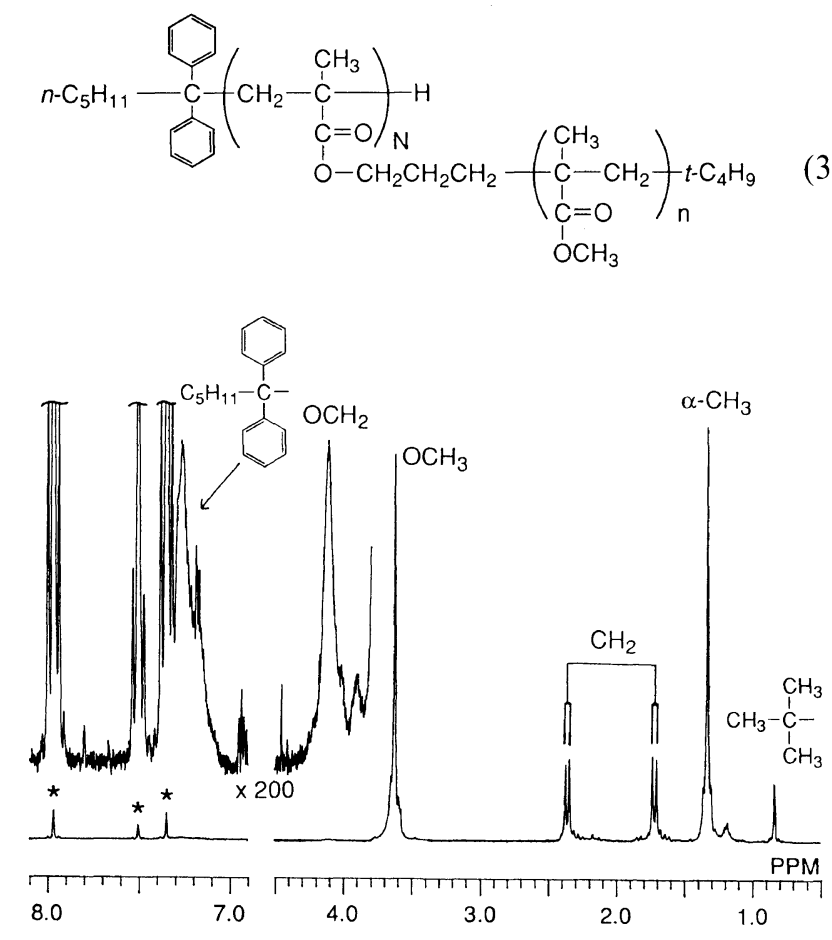

Figure 2. $500 \mathrm{MHz}{ }^{1} \mathrm{H}$ NMR spectrum measured in nitrobenzene$d_{5}$ at $110^{\circ} \mathrm{C}$ of polymer of it-PMMA macromonomer prepared with DPHLi in THF.

* Signals due to the remaining protons in nitrobenzene- $d_{5}$. 
The anionic synthesis of polymacromonomer provides us a superior way to attain the control of structures of comblike polymers including end group, as in the case of graft polymers. ${ }^{12-14}$

\section{Stereoregularity of Main Chain of the Comblike Polymer}

While the side-chain tacticity of the polymacromonomers was predetermined as that of the starting macromonomer by ${ }^{1} \mathrm{H}$ NMR analysis (see Table I), the direct determination of main-chain stereoregularity from ${ }^{1} \mathrm{H}$ NMR spectra of the polymacromonomers is rather difficult since the signals of the main-chain and side-chain methacrylate units overlapped with each other. In order to diminish the contribution of the side-chain signals, we prepared polymacromonomers whose side-chain MMA units were deuterated.

Figure 3 shows ${ }^{1} \mathrm{H}$ NMR spectra of polymers of deuterated st-PMMA macromonomer, poly(st-macromonomer- $d$ ), prepared with DPHLi in THF and with $t-\mathrm{C}_{4} \mathrm{H}_{9} \mathrm{MgBr}$ in toluene. Since the MMA units in the side chains are almost totally deuterated (see EXPERIMENTAL section), the signals observed in the regions of $\alpha-\mathrm{CH}_{3}$ and main-chain $\mathrm{CH}_{2}$ protons should mostly be those for the backbone units of the polymacromonomers. Comparison of the signal patterns of these regions reveals that the main-chain stereoregularities of the polymacromonomers prepared with DPHLi and with $t-\mathrm{C}_{4} \mathrm{H}_{9} \mathrm{MgBr}$ are syndiotactic (Figure $3 \mathrm{a}$ ) and isotactic (Figure 3b), respectively.

Quantitative determination of triad tacticity in the main chain of $s t$-poly (st-macromonomer-d) was made from the ${ }^{1} \mathrm{H}$ NMR spectrum (Figure $3 \mathrm{a}$ ) by the following procedure. The signal of $\alpha-\mathrm{CH}_{3}$ protons in $r r$ triad was observed clearly at $1.24 \mathrm{ppm}$ and its intensity, $\left[\alpha-\mathrm{CH}_{3}(r r)\right]$, could be easily determined. The $\alpha-\mathrm{CH}_{3}$ signal due to $m r$ triad was observed at $1.33 \mathrm{ppm}$. However, its intensity, $\left[\alpha-\mathrm{CH}_{3}(m r)\right]$, could not be estimated directly owing to the overlapping signal due to $r r$ triad. Instead, $\left[\alpha-\mathrm{CH}_{3}(m r)\right]$ was calculated from eq 4 , based

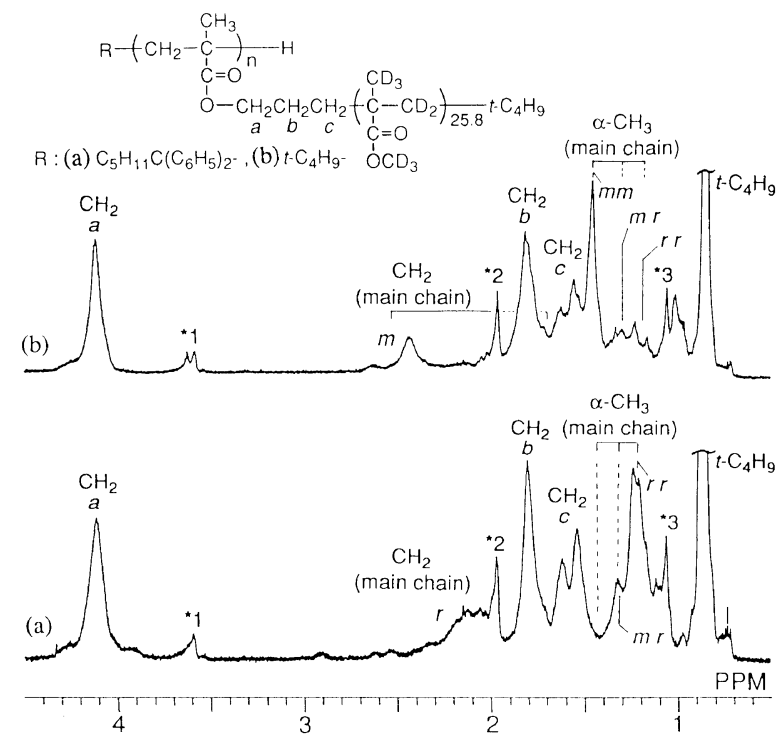

Figure 3. $500 \mathrm{MHz}{ }^{1} \mathrm{H}$ NMR spectra measured in nitrobenzene- $d_{5}$ at $140^{\circ} \mathrm{C}$ of polymers of $s t$-deuterated PMMA macromonomer prepared with DPHLi in THF (a) and with $t-\mathrm{C}_{4} \mathrm{H}_{9} \mathrm{MgBr}$ in toluene (b). $* 1, * 2, * 3$ Signals due to the remaining protons of the deuterated macromonomer: ${ }^{* 1} \mathrm{OCHD}_{2} ;{ }^{* 2} \mathrm{CHD} ;{ }^{* 3} \alpha-\mathrm{CHD}_{2}$. on the relationship, $r=r r+0.5 m r$, by using the signal intensity of $\mathrm{CH}_{2}$ protons in $r$ diad at $2.10 \mathrm{ppm},\left[\mathrm{CH}_{2}(r)\right]$.

$$
\left[\alpha-\mathrm{CH}_{3}(m r)\right]=2\left\{1.5\left[\mathrm{CH}_{2}(r)\right]-\left[\alpha-\mathrm{CH}_{3}(r r)\right]\right\}
$$

The signal of $\alpha-\mathrm{CH}_{3}$ protons in $\mathrm{mm}$ triad could not be observed clearly probably due to the peak overlapping. The total intensity of $\alpha-\mathrm{CH}_{3}$ protons, $\left[\alpha-\mathrm{CH}_{3}(r r)\right]+$ $\left[\alpha-\mathrm{CH}_{3}(m r)\right]+\left[\alpha-\mathrm{CH}_{3}(m m)\right]$, should correspond to $3 / 2$ of the intensity of $\mathrm{OCH}_{2}$ protons, $\left[\mathrm{OCH}_{2}\right]$. By using the signal of $\mathrm{OCH}_{2}$ (marked as " $\mathrm{CH}_{2} a$ " in Figure 3, at $4.11 \mathrm{ppm})$ group as an internal standard, $\left[\alpha-\mathrm{CH}_{3}(\mathrm{~mm})\right]$ could be estimated according to eq 5 .

$$
\begin{aligned}
{\left[\alpha-\mathrm{CH}_{3}(m m)\right]=} & 1.5\left[\mathrm{OCH}_{2}\right]-\left\{\left[\alpha-\mathrm{CH}_{3}(r r)\right]\right. \\
& \left.+\left[\alpha-\mathrm{CH}_{3}(m r)\right]\right\}
\end{aligned}
$$

The main-chain tacticity of the st-poly(st-macromonomer- $d$ ) thus obtained from the peak intensities, $\left[\alpha-\mathrm{CH}_{3}(r r)\right],\left[\alpha-\mathrm{CH}_{3}(m r)\right]$, and $\left[\alpha-\mathrm{CH}_{3}(m m)\right]$, are shown in Table II.

The main-chain tacticity of it-poly(st-macromonomerd) (Figure 3b) was determined as follows. The signal of $\alpha-\mathrm{CH}_{3}(\mathrm{~mm})$ was observed clearly at $1.45 \mathrm{ppm}$ and its intensity could be easily determined. $\left[\alpha-\mathrm{CH}_{3}(m r)\right]$ could be determined from the intensities of $\alpha-\mathrm{CH}_{3}(\mathrm{~mm})$ and $\mathrm{CH}_{2}(m)$ protons. It should be noted that methylene protons in $m$ diad of PMMA shows double-doublet signals $^{23}$ (see Figure 2 as an example). Therefore, a broad signal at $2.43 \mathrm{ppm}$ in Figure $3 \mathrm{~b}$ should be due to one of the $\mathrm{CH}_{2}(m)$ protons, though the splitting due to the spin-spin coupling is not recognizable. Thus, the signal intensity of the $\mathrm{CH}_{2}(m)$ protons should be twice the intensity of the peak at $2.43 \mathrm{ppm}$. $\left[\alpha-\mathrm{CH}_{3}(r r)\right]$ was estimated in a similar manner to that for $s t$-poly $(s t$ macromonomer- $d$ ).

Main-chain tacticities of polymers of it-macromonomer- $d$ were also determined by the same procedures as described above.

Table II summarizes the results of the structural analyses of four types of poly(macromonomer- $d$ )s. The side-chain tacticities shown in Table II are values of the starting macromonomers which were determined from ${ }^{1} \mathrm{H}$ NMR analyses for remaining protons in $\alpha$-methyl group, and the values are almost the same as those of the corresponding non-deuterated macromonomers (see Table I). The main-chain tacticity of poly(macromonomer- $d$ ) prepared with DPHLi in THF is syndiotactic and almost the same as the value of PMMA formed under similar conditions. ${ }^{20}$

On the other hand, the main-chain tacticity of poly(macromonomer- $d$ ) prepared with $t-\mathrm{C}_{4} \mathrm{H}_{9} \mathrm{MgBr}$ in toluene is predominantly isotactic, though the isotacticity is lower than that of PMMA obtained under similar conditions. ${ }^{17}$ The polymerizations of methacrylates having linear alkyl ester group by $t-\mathrm{C}_{4} \mathrm{H}_{9} \mathrm{MgBr}$ in toluene give highly isotactic polymer; even lauryl methacrylate gives an isotactic polymer ( $m m: m r: r r=97: 2: 1) .{ }^{24} \mathrm{On}$ the contrary, $t$-butyl methacrylate gives a less stereoregular polymer $(m m: m r: r r=48: 26: 26),{ }^{25}$ suggesting that stereospecificity is affected more strongly by the structure near the ester linkage rather than by the length of alkyl group. The macromonomer has a branch at $\delta$-position from the methacryloyl function where the ester 
group of MMA unit attaches. The coordination of this ester group in the living-end unit to the counterion, if it occurs, might give rise to the lower isotacticity in the main chain of the polymacromonomer.

The results summarized in Table II show that stereospecific polymerizations of stereoregular macromonomers gave comblike polymers with controlled stereoregularities in main chain and in side chain. Thus, we can conclude that the knowledge on stereospecificity of polymerization of methacrylates is applicable to the polymerization of the methacrylate-type macromonomers.

\section{REFERENCES}

1. R. Milkovich and M. T. Chiang, U.S. Patent, 3,786, 116 (1974); R. Milkovich, Polym. Prepr., Polym. Chem. Div., Am. Chem. Soc., 21, 40 (1980).

2. P. F. Rempp and E. Franta, Adv. Polym. Sci., 58, 1 (1984).

3. Y. Yamashita, J. Appl. Polym. Sci., Appl. Polym. Symp., 36, 193 (1985).

4. R. Asami and M. Takaki, Makromol. Chem., Rapid Commun., 12, 163 (1985).

5. K. Ito, Kobunshi Kako (Polymer Application), 35, 262 (1986).

6. K. Hatada, H. Nakanishi, K. Ute, and T. Kitayama, Polym. J., 18, 581 (1986).

7. K. Hatada, T. Shinozaki, K. Ute, and T. Kitayama, Polym. Bull., 19, 231 (1988)

8. K. Hatada, T. Kitayama, K. Ute, E. Masuda, T. Shinozaki, and M. Yamamoto, Polym. Bull., 21, 165 (1989).

9. K. Hatada, T. Kitayama, E. Masuda, and M. Kamachi,
Makromol. Chem., Rapid Commun., 11, 101 (1990).

10. E. Masuda, S. Kishiro, T. Kitayama, and K. Hatada, Polym. J., 23, 847 (1991).

11. T. Kitayama, S. Kishiro, and K. Hatada, Polym. Bull., 25, 161 (1991).

12. T. Kitayama, O. Nakagawa, S. Kishiro, T. Nishiura, and K. Hatada, Polym. J., 25, 707 (1993).

13. K. Hatada and T. Kitayama, "Macromolecular Design: Concept and Practice, (Macromonomers, Macroinitiators, Macroiniferters, Macroinimers, Macroiniters, and Macroinifers)," Polymer Frontiers International, Inc., New York, N.Y., 1994, pp 85-127.

14. T. Kitayama, O. Nakagawa, and K. Hatada, Polym. J., 27, 1180 (1995).

15. H. Yuki and K. Hatada, Adv. Polym. Sci., 31, 1 (1979).

16. K. Hatada, T. Kitayama, and K. Ute, Prog. Polym. Sci., 13, 189 (1988).

17. K. Hatada, K. Ute, K. Tanaka, Y. Okamoto, and T. Kitayama, Polym. J., 18, 1037 (1986).

18. B. C. Anderson, G. D. Andrews, P. Arthur, Jr., H. W. Jacobson, L. R. Melby, A. J. Playtis, and W. H. Sharkey, Macromolecules, 14, 1599 (1981).

19. P. Luts, P. Masson, G. Beinert, and P. Rempp, Polym. Bull., 12, 79 (1984).

20. Z-K. Cao, Y. Okamoto, and K. Hatada, Kobunshi Ronbunshu, 43, 857 (1986)

21. K. Hatada, Y. Terawaki, and H. Okuda, Org. Magn. Reson., 9, 518 (1977).

22. K. Hatada, T. Kitayama, Y. Okamoto, K. Ohta, Y. Umemura, and H. Yuki, Makromol. Chem., 179, 485 (1978).

23. A. Nishioka, H. Watanabe, K. Abe, and Y. Sono, J. Polym. Sci., 48, 241 (1960)

24. T. Kitayama, O. Nakagawa, and K. Hatada, unpublished result.

25. T. Kitayama, S. He, Y. Hironaka, T. Iijima, and K. Hatada, Polym. J., 27, 314 (1995) 